\title{
Seismic Behavior and Detailing of High-Performance Fiber- Reinforced Concrete Coupling Beams and Coupled Wall Systems
}

\author{
Rémy D. Lequesne ${ }^{1}$, Gustavo J. Parra-Montesinos ${ }^{2}$, and James K. Wight ${ }^{3}$
}

\begin{abstract}
The seismic behavior of coupling beams and walls constructed with tensile strain-hardening, high-performance fiber-reinforced concrete (HPFRC) was studied through tests of large-scale precast coupling beams and coupled walls. A precast coupling beam design was developed to speed up construction and minimize interference with wall reinforcement. Three isolated precast coupling beam specimens with a span-to-depth ratio of 1.75 were tested under large displacement reversals. Test results indicate the use of HPFRC allows a reduction of the reinforcement required to achieve a stable coupling beam response by providing confinement and contributing to beam shear strength. A concrete design shear stress capacity of $0.41 \sqrt{ } f_{c}{ }^{\prime},[\mathrm{MPa}]\left(5 \sqrt{ } f_{c}{ }^{\prime}\right.$, [psi]), where $f_{c}{ }^{\prime}$ is the compressive strength of the concrete, was found to be appropriate. In addition to the coupling beam tests, two four-story coupled wall specimens with precast HPFRC and regular concrete coupling beams were tested under lateral displacement reversals. Besides allowing the evaluation of seismic behavior of coupled walls with HPFRC coupling beams, the use of HPFRC in the plastic hinge regions of the walls as a means of relaxing transverse wall reinforcement was evaluated. The two coupled wall specimens exhibited drift capacities of at least $2.5 \%$. The HPFRC coupling beams were more ductile and damage tolerant than the regular concrete beams. The incorporation of an HPFRC material in the wall allowed the use of a concrete design shear stress capacity of $0.33 \sqrt{ } f_{c}^{\prime}$, , [MPa] $\left(4 \sqrt{ } f_{c}^{\prime}\right.$, [psi]) and a wider spacing of transverse reinforcement confining the wall boundary regions.
\end{abstract}

Keywords: Coupled Walls, Coupling Beams, Reinforced Concrete, Precast Concrete, Fibers, Confinement, Shear, Drift

\footnotetext{
${ }^{1}$ Struct. Engr., Wiss, Janney, Elstner Associates, Inc., 330 Pfingsten Rd, Northbrook, IL 60062

${ }^{2}$ Assoc. Prof., Dept. of Civ. and Envir. Engrg., Univ. of Michigan, 2350 Hayward, Ann Arbor, MI, 48109-2125

${ }^{3}$ Prof., Dept. of Civ. and Envir. Engrg., Univ. of Michigan, 2350 Hayward, Ann Arbor, MI, 48109-2125
} 


\section{INTRODUCTION}

Concrete structural walls linked by coupling beams are commonly used as the primary lateral force resisting system for medium- to high-rise structures. In an earthquake, the coupled walls provide lateral stiffness and energy dissipation. To ensure adequate seismic performance and minimize repair costs, the coupling beams and walls must be capable of sustaining large inelastic deformations and exhibit significant tolerance to displacement-induced damage. For the particular case of coupling beams, ductile behavior is achieved through the use of diagonal bars designed to resist the entire shear demand in combination with large amounts of confinement reinforcement. This special reinforcement detailing is expected to delay or prevent non-ductile shear and compression-related failures. Although effective, the difficulty of assembling this reinforcement detailing in a cost-effective and timely manner has motivated numerous studies aimed at finding alternatives. These have included various reinforced concrete, steel and composite coupling beams. None of these alternatives, however, have been widely implemented by the structural engineering community due to either constructability or performance issues.

The purpose of this study was to investigate the use of tensile strain-hardening, high-performance fiber-reinforced concrete (HPFRC) as a means to simplify reinforcement detailing in coupling beams. In addition, the use of HPFRC in the plastic hinge regions of walls was also investigated as a means to increase shear strength and reduce wall boundary confinement reinforcement. The post-cracking tensile resistance and strain capacity of HPFRC materials, combined with a compression response that resembles that of well-confined concrete, indicates that these materials can be used as partial replacement for transverse reinforcement used for confinement and shear resistance (Parra-Montesinos 2005).

\section{PREVIOUS RESEARCH}

Numerous researchers have sought to design ductile coupling beams since Paulay (1971) first published test results showing that short and highly stressed coupling beams reinforced with conventional longitudinal bars and sufficient transverse reinforcement to prevent a diagonal tension failure are susceptible to sliding shear failures under large displacement reversals. The results from the first of these subsequent studies (Paulay and Binney, 1974), demonstrated that diagonally reinforced coupling beams exhibit a considerably more ductile response than beams reinforced with conventional beam-type reinforcement. This diagonal reinforcement design became the state-of-the-art and design provisions have been included in the ACI Building Code since 1999 (ACI Committee 318 1999). In the ACI Building Code, diagonal reinforcement is required in coupling beams with $l_{n} / h<2$ and $v_{u}>0.33 \sqrt{ } f_{c}$, [MPa] ( $4 \sqrt{ } f_{c}$, [psi]), where: $l_{n}=$ clear span of coupling beam, $h=$ height of coupling beam, $v_{u}=$ shear stress demand, and $f_{c}{ }^{\prime}=$ compressive strength of concrete. Unfortunately, diagonally reinforced coupling beams require heavy confinement of the diagonal reinforcement resulting in reinforcement congestion severe enough to cause construction of coupling beams to often control the construction schedule of buildings in seismic zones (Harries 2005; Lequesne et al. 2011).

Many alternatives have been investigated to improve the constructability of coupling beams without compromising performance under reversed cyclic loading. These alternatives have included adding dowel bars in the plastic hinging region of beams reinforced with conventional beam-type 
detailing, "rhombic" type reinforcement, which provides unconfined diagonal bars through the plastic hinge (Shiu et al. 1978; Galano and Vignoli 2000; Tassios et al. 1996), and diagonally reinforced coupling beams with alternative or reduced confinement detailing (Fortney et al. 2008; Naish et al. 2009). Of these alternatives, only the full-section confinement tested by Naish et al. was shown to provide sufficiently stable performance to justify a change from the state of the art and adoption by the ACI Building Code (Committee 318 2008). Other alternatives, including steel and hybrid steel-concrete coupling beams have also been investigated (summarized by Harries et al. 2000) and used in practice. These coupling beams have been shown to provide greater strength, ductility and energy dissipation than reinforced concrete coupling beams. However, embedment of the steel beam leads to interference with longitudinal and transverse reinforcement in the wall boundary regions. The special detailing required to accommodate the steel beam and provide confinement to the wall boundary element, as well as the need for coordination between steel and concrete trades, has prevented widespread adoption by industry.

Recent work (Canbolat et al. 2005) on very short coupling beams $\left(l_{n} / h=1.0\right)$ demonstrated the potential for HPFRC to provide improved ductility over traditional concrete coupling beams despite simplified reinforcement detailing. These results are consistent with findings from tests of HPFRC beamcolumn connections and walls, which have indicated that HPFRC increases shear strength and confinement in elements subjected to load reversals (Parra-Montesinos 2005). The coupling beam tests by Canbolat et al. showed that HPFRC provides confinement to the concrete and diagonal reinforcement and actively resists shear stresses through large displacement reversals.

\section{RESEARCH SIGNIFICANCE}

The investigation presented herein includes large scale tests of precast HPFRC coupling beams and coupled walls. A method for embedding precast HPFRC coupling beams into walls was tested that minimizes interference with wall reinforcement and does not require the reinforcement cage to be in place prior to wall concrete being cast immediately below the coupling beam level. These tests have provided data regarding the confinement and shear capacity contributed by the HPFRC material, leading to specific design recommendations for HPFRC coupling beams. It is the first study in which coupled walls with HPFRC components have been tested, and also includes one of few tests on T-shaped reinforced concrete walls. The wall tests provided data regarding the interactions between coupling beams, slabs and walls, which were used to develop design recommendations for HPFRC coupled-wall systems.

\section{EXPERIMENTAL PROGRAM}

\section{Coupling Beam Specimens}

Three coupling beam specimens were built at approximately two-thirds scale and pseudostatically subjected to reversed cyclic displacements that increased in magnitude until failure of the specimen. Each specimen consisted of a precast HPFRC coupling beam connected to stiff reinforced concrete blocks that simulated structural wall boundary elements. A diagram of the test setup is shown in 
Figure 1. The coupling beam specimens were rotated 90 degrees with respect to the field orientation for testing convenience. One end block was bolted to the laboratory strong floor to approximate a fixed boundary condition, while a hydraulic actuator applied lateral displacements to the other. The top block was restrained from rotating by steel links that also provided passive restraint to coupling beam elongation. This passive restraint is similar to the restraint provided by stiff structural walls (Teshigawara et al. 1998). Coupled wall test results presented herein showed the degree of passive restraint provided was more realistic than the free elongation often permitted in tests.

The coupling beam specimen reinforcement is shown in Figure 2. Two reinforcement details were tested for embedding the precast HPFRC coupling beam into the adjacent walls. The goal was to develop a constructible detail that minimizes interference with wall reinforcement and prevents localization of damage at the connection under inelastic displacement demands. The diagonal reinforcement was bent near the wall face, which permitted the diagonal bars to be developed horizontally into the wall parallel to the boundary element hoops. This detail eliminates the difficult task of threading bars diagonally through multiple layers of hoops. The bent-diagonal detail permits beam construction after wall concrete has been cast up to the bottom level of the beam, allowing for more flexible construction sequencing. The precast portion, which is shaded in grey in Figure 2, only extended $25 \mathrm{~mm}$ (1 in.) into the wall. Dowel bars were included to prevent damage from localizing at the cold joint. The size and location of the dowel bars were selected so that the demand to capacity ratio was smaller at the interface with the wall than at the dowel bar bend or cutoff section within the beam, thereby forcing most inelastic flexural rotations into the beam. In Specimens CB-1 and CB-2, U-shaped dowel bars extended $100 \mathrm{~mm}$ (4 in.) into the beam span. Straight dowel bars extended $175 \mathrm{~mm}$ (7 in.) into the span of Specimen CB-3. The dowel bar development was selected based on testing by Chao (2005). Specimens CB-1 and CB-2 had shear keys to provide additional resistance to sliding shear displacements; Specimen CB-3 did not.

Aside from the connection, the reinforcement of the specimens differed in several important ways from that currently required for reinforced concrete coupling beams. The specimens were reinforced with diagonal bars sized to resist approximately one-third of the expected coupling beam shear demand instead of the entire shear demand required for code-compliance. The shear demand not resisted by diagonal bars was assumed to be resisted by the combined action of transverse hoops and HPFRC. Outside of the plastic hinge regions, assumed to extend half the beam depth $(h / 2)$ from each end, the transverse reinforcement ratio, calculated as the cross-sectional area of one hoop divided by the product of the beam width and hoop spacing, was $0.60 \%$ for Specimens CB-1 and CB-2, and $0.45 \%$ for Specimen CB-3. Confinement of the diagonal reinforcement in this region was assumed to be provided by the HPFRC material. Closed hoops with a transverse reinforcement ratio approximately equal to that required by the ACI Building Code (318-08) for special column confinement were placed within $h / 2$ of the ends of the beam in Specimens CB-2 and CB-3 after testing of Specimen CB-1 demonstrated the need for hoops throughout the plastic hinge. Straight longitudinal (flexural) reinforcement was placed along the top and bottom of the beam to increase the moment capacity of the coupling beams. Intermediate longitudinal reinforcement provided improved plastic hinge stability at large drift and shear stress demands, and enhanced cracking distribution in the midspan of the coupling beam. 


\section{Coupled Wall Specimens}

Two four-story coupled wall specimens were constructed at approximately one-third scale, and pseudo-statically subjected to reversed cyclic displacements until failure. Each specimen consisted of four coupling beams that linked two T-shaped structural walls. The walls were oriented with the T-flanges along the outside edges of the system. Lateral displacements were applied to the specimen by two hydraulic actuators acting through slabs constructed at the second and fourth levels. Vertical load was applied to the specimen at the second level that was equivalent to approximately $7 \%$ of $A_{g} f_{c}$ ', where $A_{g}$ is the gross wall area. The vertical force simulated gravity loads typical of coupled walls found in practice.

The reinforcement of the specimens is shown in Figure 3. Both specimens had a precast reinforced concrete coupling beam at the second level and precast HPFRC coupling beams at the other three. For construction, the precast coupling beams were supported by formwork until the wall concrete was cast. The walls of Specimen CW-1 were constructed with regular reinforced concrete and designed in accordance with ACI 318-08. All straight longitudinal reinforcement in the coupling beams was terminated near the face of the wall in an effort to be more consistent with ACI 318-08 recommendations, a detail which differed from the component test specimens. The first two stories of the Specimen CW-2 walls were constructed with HPFRC. They were reinforced with more widely spaced boundary element confinement reinforcement and designed with a higher concrete shear stress contribution. All coupling beam reinforcement was developed into the walls of Specimen CW-2. Specimens CW-1 and CW-2 were designed to have coupling ratios of approximately 0.45 and 0.50 , respectively.

\section{Material Properties}

Both HPFRC and conventional concrete were used to construct the specimens in this study. The HPFRC mixture design, which was developed by Liao et al. (2006), is shown in Table 1. It includes a $1.5 \%$ volume fraction $\left(V_{f}\right)$ of high-strength hooked steel fibers and coarse aggregate with a maximum nominal diameter of $13 \mathrm{~mm}$ (0.5 in.). The fibers are $30 \mathrm{~mm}$ (1.2 in.) long, have a diameter of $0.38 \mathrm{~mm}$ (0.015 in.), a length to diameter ratio of 80 , and a minimum tensile strength of $2300 \mathrm{MPa}$ (333 ksi). Direct tension tests and flexural tests done in accordance with ASTM 1609 (2005) demonstrated that this mixture exhibits both deflection-hardening in bending and strain-hardening in tension. The conventional concrete used contained coarse aggregate with a maximum nominal diameter of $13 \mathrm{~mm}(0.5 \mathrm{in}$.) with specified compressive strengths $\left(f_{c}{ }^{\prime}\right)$ of either 28 or $41 \mathrm{MPa}$ (4 or $6 \mathrm{ksi}$ ). The results of tests done on samples taken from pours of selected regions of the structures are given in Table 2. Sample results from tensile tests on $200 \mathrm{~mm}$ ( 8 in.) long specimens with cross sections of 25 by $50 \mathrm{~mm}$ ( 1 by 2 in.) are plotted in Figure 4. The low compressive strength of the first lift of Specimen CW-2 was the result of a problem the day of casting. The design $f_{c}$ ' of $41 \mathrm{MPa}(6 \mathrm{ksi})$ is assumed herein for calculations of normalized shear stress. Complete material properties can be found in Lequesne (2011).

Mild deformed steel reinforcement with a minimum yield strength of $415 \mathrm{MPa}(60 \mathrm{ksi})$ and an ultimate strength greater than $620 \mathrm{MPa}(90 \mathrm{ksi}$ ) was used for bars of size D10 (\#3) and larger. The size D6 (\#2) steel used for confining the wall boundary elements was smooth steel wire with yield and ultimate strengths of approximately 415 and $500 \mathrm{MPa}$ (60 and $73 \mathrm{ksi}$ ), respectively. Results of coupon tests of reinforcement can be found in Lequesne (2011). 


\section{RESULTS}

\section{Coupling Beam Specimens}

In general, it was shown that HPFRC coupling beams with an aspect ratio of 1.75 exhibit excellent damage tolerance and a drift capacity of approximately 5\% when detailed properly. The test results are summarized in Table 3. A plot of the shear stress vs. drift response for each specimen is shown in Figure 5, where shear stress was calculated as the shear force divided by the gross cross-sectional area and drift is the imposed displacement divided by the initial beam length, corrected for end block rotation. The damage in each specimen at drift capacity is shown in Figure 6, where drift capacity is defined as the largest drift to which $80 \%$ of peak shear force was sustained. The dense array of cracks is evidence of the HPFRC's ability to deform more uniformly, leading to the high damage tolerance of the specimens.

At drift demands up to $2 \%$, Specimen CB-1 exhibited stiffness and hysteresis characteristics comparable to a well detailed diagonally reinforced concrete coupling beam. Despite the high shear stresses imposed (a peak of $1.07 \sqrt{ } f_{c}$, , [MPa] $\left(12.8 \sqrt{ } f_{c}\right.$, [psi]) was reached near $2 \%$ drift) moderately wide hysteresis loops and crack patterns showed that yielding of the diagonal and flexural reinforcement controlled the response. However, Specimen CB-1 lost its lateral load capacity when displaced beyond $2 \%$ drift. This reduced drift capacity was attributed to inadequate confinement of the plastic hinge region evidenced by transverse (out-of-plane) beam expansion and buckling.

The response of Specimen CB-2, which is representative of the proposed design, was characterized by full hysteresis loops with minor pinching, indicating good energy dissipation. The improved performance of Specimen CB-2 compared to Specimen CB-1 showed that special column-type confinement is required in the coupling beam within $h / 2$ of the face of the wall where the diagonal reinforcement is bent. Measurements of crack widths showed that at $1 \%$ drift, all diagonal and flexural cracks were less than $1 \mathrm{~mm}$ (0.04 in.) wide. At 3.5\% drift, flexural cracks near the ends of the beam had opened to approximately $2.5 \mathrm{~mm}$ ( $0.1 \mathrm{in}$.), but all diagonal cracking remained less than $1 \mathrm{~mm}(0.04 \mathrm{in}$.) wide throughout the test. At 5.5\% drift, shear sliding was observed along the most severe flexural cracking planes after flexural cracks had opened wider than $3.5 \mathrm{~mm}$ (0.15 in.).

The performance and damage observed in the test of Specimen CB-3 were similar to those of Specimen CB-2 despite reduced transverse reinforcement in the middle of the span. The 25 percent reduction in transverse reinforcement ratio did not lead to increased diagonal crack widths, indicating that the HPFRC effectively worked with the diagonal and transverse reinforcement to limit crack widths.

Both details for shallowly embedding the precast beam were effective at moving the damage away from the cold joint at the precast beam-to-wall interface and into the precast beam. The dowel bars were critical for relocating the damage and are a required feature of the design. Strain gauge readings indicated that the dowel bars yielded, showing the development length was appropriate. Shear keys in the first two specimens and eliminated in Specimen CB-3 were shown to be less important because sliding shear displacements at the cold joint increased only marginally after their removal.

\section{Elongation and Axial Force}

Reinforced concrete members subjected to in-elastic cyclic displacements expand longitudinally. In most design cases, the resulting axial strain is either small or insufficiently restrained to cause development of significant axial forces. However, the large drift demands placed on short coupling beams 
result in a strong tendency to expand longitudinally, and the adjacent structural walls provide nonnegligible resistance to this expansion (Teshigawara et al. 1998). In component tests, few researchers have addressed longitudinal expansion of coupling beams and the possible axial forces that may develop. Most experimental work has allowed for unlimited axial growth, which has been reported to be on the order of 3.0\% of the beam span (Kwan and Zhao 2002; Naish et al. 2009). In the current series of tests, passive restraint to longitudinal expansion resulted in maximum average axial strains between 0.6-1.4\%. At any point in the loading sequence, the axial strain was closely related to the peak specimen drift previously imposed. Repeated loading at constant drift levels and loading cycles to smaller drift levels did little to increase the longitudinal coupling beam growth.

Passive longitudinal restraint of the coupling beam specimens resulted in axial stresses on the order of 4-7\% of $A_{g} f_{c}$. Although relatively small in magnitude, the axial forces developed may impact the stiffness of the beam and were shown by analysis to increase the flexural capacity of the specimens by approximately $20 \%$. Assuming flexural strength governs the beam capacity, this larger flexural capacity increases the coupling beam shear demand, which may impact the design and performance of both the beams and walls. In addition, axial forces tend to increase the coupling beam sliding shear resistance while making the reinforcement more susceptible to buckling.

\section{Flexural Behavior}

The specimen responses were controlled by ductile flexural hinges at each end of the coupling beams. On the basis of measured deformations, the flexural hinges were estimated to extend approximately $h / 2$ into the coupling beam and eight diagonal bar diameters into the wall past the precast beam embedment length. Based on results from an infrared marker system used to measure deformations, it was estimated that each hinge developed rotations in excess of 0.03 radians, accounting for approximately $50-70 \%$ of the total specimen drift.

For predicting the capacity of the flexural hinges, a nominal moment capacity calculation that assumed the reinforcement had yielded and neglected axial loads and contributions from HPFRC provided a reasonable lower bound capacity that was reached at $0.75 \%$ drift and sustained until failure of the tested specimens. However, to ensure sufficient coupling beam shear capacity is provided and to more accurately predict the axial loads in the walls, an accurate estimate of the peak flexural capacity is necessary. The peak capacity was predicted to within $\pm 6 \%$ for the specimens tested using a moment calculation performed at the beam end and at the dowel bar cutoff in which steel stresses were taken equal

to $1.25 f_{y}$, where $f_{y}$ is the nominal yield stress, tension stresses in the HPFRC were neglected, and the section axial force was equal to $0.4 V_{u}$.

\section{Shear Behavior}

Despite the large shear stresses imposed on coupling beams, shear deformations must be limited and shear failures prevented for a ductile flexural response to be achieved. In the specimens tested, shear capacity was provided by diagonal reinforcement, transverse hoops, and the HPFRC material. Strain gauges placed on the diagonal reinforcement indicated they were active and resisted approximately 20$25 \%$ of the peak shear imposed, assuming a fixed crack angle of 45 degrees. No buckling of the diagonal bars was observed, indicating that the HPFRC and the reduced transverse reinforcement were sufficient for providing confinement outside of the beam plastic hinge region. Strain gauges placed on the 
transverse hoops indicated they were active throughout the test (after first cracking, which occurred at an average shear stress of approximately $0.19 \sqrt{ } f^{\prime}{ }_{c}$ [MPa] $\left(2.3 \sqrt{ } f^{\prime}{ }_{c}\right.$ [psi]). Based on strain gauge readings, it was estimated the hoops resisted approximately $25-40 \%$ of the peak imposed shear outside of the beam plastic hinges. Unlike reinforced concrete coupling beams, for which it is recommended that the shear capacity of hoops be neglected, hoops in HPFRC coupling beams can be considered active because the improved damage tolerance of these members ensures spalling will be reduced and the core remains sufficiently sound throughout the loading sequence to sustain a truss mechanism. The remaining shear demand was resisted by the HPFRC through a combination of shear carried in the compression zone, dowel action, aggregate interlock along fine cracks, and direct transfer of tensile stresses across cracks. These mechanisms contributed an average shear stress as large as $0.55 \sqrt{ } f_{c}^{\prime}$ [MPa] $\left(6.7 \sqrt{ } f_{c}^{\prime}\right.$ [psi]), representing $40-50 \%$ of the peak shear imposed. Shear distortions calculated for the midspan region of Specimen CB-2 using infrared marker data showed that average shear distortions peaked at approximately 0.006 rad. For comparison, tests of reinforced concrete joints have shown that cyclic shear degradation begins at shear distortions of $0.01 \mathrm{rad}$. Based on these results, which showed that large cyclic shear stresses corresponded with moderate and stable shear distortions, it is recommended that an average design shear stress of $0.40 \sqrt{ } f_{c}{ }_{c}$ [MPa] $\left(5 \sqrt{ } f_{c}^{\prime}{ }_{c}\right.$ [psi]) be used to estimate the contribution of HPFRC to the coupling beam shear capacity in the midspan region.

\section{Coupled Wall Specimens}

The overturning moment versus drift response of Specimens CW-1 and CW-2 is plotted in Figure 7, and the results are summarized in Table 4. Both specimens performed in a stable and ductile manner, retaining $80 \%$ of peak capacity to $2.5 \%$ system drift in both loading directions. At drift demands up to $0.75 \%$, both specimens developed predominantly diagonal cracking in the coupling beams and walls. The diagonal cracks in the reinforced concrete walls were spaced at approximately $125 \mathrm{~mm}$ (5 in.), whereas those in the HPFRC walls were narrower and more numerous, spaced at approximately $50 \mathrm{~mm}(2 \mathrm{in}$.). Both specimens developed diagonal cracking in the first story of the wall under compression and in the second story in the wall under tension that effectively spread the predominant diagonal cracking throughout a height equivalent to the distance between the outer edges of the coupled walls. As drift demands increased and flexural hinging developed in the coupling beams, flexural cracking developed near the wall bases and spread to a height approximately equal to the individual wall depth. The crack patterns after testing are shown in Figure 8.

The behavior of Specimen CW-1 was governed by flexural yielding at the base of both wall piers, with damage in all four coupling beams localized along the precast beam-to-wall boundary. This undesirable localization of damage was not observed in the component tests and is attributable to the cutoff longitudinal bar detail. The overall specimen response was not compromised, but this localization of damage did not allow the coupling beams to develop as much energy as possible. Full development of all beam reinforcement into the walls, as was done in Specimen CW-2, will prevent this.

Specimen CW-2 exhibited damage throughout the coupling beams away from the connection. At a system drift of approximately $0.75 \%$, the reinforced concrete coupling beam began to exhibit more severe cracking than the HPFRC beams. By $2 \%$ system drift, which corresponded to approximately $6 \%$ coupling beam drift, the concrete in the reinforced concrete beam had begun to spall leaving stirrups 
exposed, whereas the HPFRC beams were still relatively intact. By the end of the test at a system drift of $3.6 \%$, the reinforced concrete beam had sustained significant damage to its core, whereas the HPFRC beams were still functional (Figure 9). This emphasizes the improved damage tolerance exhibited by the HPFRC coupling beams. It should be noted that, despite performing in a ductile manner, both coupling beams one and four in Specimen CW-2 exhibited damage different from that observed in component tests. The difference has been attributed to large compression forces from the loading mechanism (beam one) and incorrectly placed dowel reinforcement (beam four). Specimen CW-2's HPFRC walls developed plastic flexural hinges despite reduced shear and confinement reinforcement. At a system drift of $2.5 \%$ a shear-compression failure occurred in one wall.

\section{Coupling Beam Deformation}

The drift demands on the coupling beams were magnified with respect to the drift demands on the system (generally by a linear factor of 3 for these specimens). Coupling beams in both wall systems were subjected to drift demands larger than $8 \%$ when the system drift reached $2.5 \%$. This amplification of component drift demand is primarily a function of the system geometry, and is why coupling beam ductility and damage tolerance are such critical design goals. As shown in Figures 8 and 9, the more damage tolerant HPFRC coupling beams can accommodate these large drift demands without sustaining critical section loss despite being more lightly reinforced transversely.

In addition to drift, the longitudinal deformation of the coupling beams was measured and compared to the restraint provided to the component specimens to investigate whether walls and slabs confine coupling beams. The longitudinal deformations of the coupling beams in Specimen CW-1 are shown in Figure 10, plotted against the coupling beam drift. Coupling beams at the second through fourth levels developed average longitudinal strains between 0.005 and 0.017 at coupling beam drifts exceeding $2 \%$. This is consistent with the strains developed in the component tests, which ranged between 0.007 and 0.014 for the same range of drifts. These longitudinal strains are more consistent with passively restrained beams than with beams that are free to expand longitudinally.

\section{Wall Strength and Boundary Confinement}

The reinforced concrete walls in Specimen CW-1 were designed in accordance with ACI 318-08, with an assumed concrete shear strength of $0.17 \sqrt{ } f^{\prime}{ }_{c}$ [MPa] $\left(2 \sqrt{ } f^{\prime}{ }_{c}\right.$ [psi]) and a boundary confinement reinforcement spacing of $b_{w} / 3$. These walls developed ductile flexural hinges that showed no indication of shear distress despite average base shear stress demands of up to $0.46 \sqrt{ } f_{c}{ }_{c}$ [MPa] (5.6 $\sqrt{ } f^{\prime}{ }_{c}$ [psi]), based on the concrete cylinder compression strength at test day. The flanged compression zones in the walls appeared to be adequately confined with no indication of buckling or crushing of concrete.

In Specimen CW-2, the walls were detailed with reduced transverse reinforcement to account for the effects of incorporating HPFRC. A concrete shear strength of $0.33 \sqrt{ } f^{\prime}{ }_{c}$ [MPa] $\left(4 \sqrt{ } f^{\prime}{ }_{c}\right.$ [psi]) was used in design and boundary confinement reinforcement was spaced at $b_{w} / 2$ and $b_{w}$, in the east and west wall, respectively, to evaluate two levels of relaxed boundary confinement in a single test. The ductile flexurally dominated response in both walls that allowed the system to reach $2.5 \%$ and $-3.6 \%$ drift while sustaining average shear stress demands as high as $0.61 \sqrt{ } f_{c}{ }_{c}[\mathrm{MPa}]\left(7.4 \sqrt{ } f^{\prime}{ }_{c}\right.$ [psi]) indicate these reduced reinforcement details are appropriate for walls in coupled systems (calculation of average base shear stress in Specimen CW-2 assumes the design $f_{c}$ ' of $41 \mathrm{MPa}[6 \mathrm{ksi}]$ ). A shear-compression failure 
eventually developed at a system drift of $2.5 \%$ in the west wall, the wall with boundary confinement reinforcement spaced at $b_{w}$. Although analysis indicated that shear-compression deformations in the web, triggered by poor concrete, caused the failure and not the spacing of boundary confinement reinforcement, this test alone does not justify spacing boundary confinement reinforcement at $b_{w}$. However, the large deformations developed prior to this failure, and the ductile performance of the opposite wall, justify recommending $v_{H P F R C}=0.33 \sqrt{ } f_{c}{ }_{c}[\mathrm{MPa}]\left(4 \sqrt{ } f_{c}{ }_{c}\right.$ [psi]) for design of HPFRC walls and spacing confinement reinforcement in the boundary elements at $b_{w} / 2$.

\section{SUMMARY AND CONCLUSIONS}

The following conclusions are drawn based on the experimental results presented:

- Precast HPFRC coupling beams are ductile and more damage tolerant than reinforced concrete coupling beams. HPFRC walls exhibited narrower cracks at a closer spacing despite reduced reinforcement.

- Coupling beams can be precast without interfering with wall reinforcement if adequate dowel reinforcement is placed crossing the cold joint. The bent diagonal detail allows for construction of the beam after wall concrete has been cast up to the bottom level of the beam. Shear keys at the cold joint are not required.

- In HPFRC coupling beams, the required area of diagonal reinforcement can be reduced by as much as $70 \%$ relative to a code-compliant design for beam aspect ratios near 1.75 .

- Confinement reinforcement in the form of hoops need only be placed in the coupling beam within $h / 2$ of the wall face, where $h$ is the height of the coupling beam. The tensile strain-hardening behavior of the HPFRC results in adequate beam confinement for the rest of the span.

- Stirrups should be considered when calculating the shear capacity of HPFRC coupling beams. A design shear stress value of $0.40 \sqrt{ } f_{c}$, [MPa] $\left(5 \sqrt{ } f_{c}\right.$ ' [psi]) is proposed for the HPFRC contribution to coupling beam strength.

- A maximum spacing of wall boundary element confinement reinforcement of $b_{w} / 2$ was found to be adequate in HPFRC walls and a design value of $0.33 \sqrt{ } f_{c_{c}}$ [MPa] $\left(4 \sqrt{ } f_{i_{c}}\right.$ [psi]) is proposed for the contribution of HPFRC to shear stress capacity in structural walls.

- Terminating coupling beam longitudinal reinforcement within the wall near the coupling beam-towall interface is not recommended. This detail caused a concentration of damage along the cold joint interface in coupled wall Specimen CW-1.

- The ACI 318-08 requirements for structural wall design provided sufficient shear and confinement reinforcement to allow the development of a ductile flexural mechanism with wall drift capacity greater than $2.5 \%$.

\section{REFERENCES}

American Concrete Institute (ACI), Committee 318 (1999). Building Code Requirements for Structural Concrete (ACI 318-99), Farmington Hills, MI, 391 pp.

ACI, Committee 318 (2008). Building Code Requirements for Structural Concrete (ACI 318-08), Farmington Hills, MI, 430 pp. 
ASTM International, Standard C1609/C1609M, (2005). "Standard Test Method for Flexural Performance of Fiber-Reinforced Concrete (Using Beam With Third-Point Loading)," West Conshohocken, PA.

Canbolat, B. A., Parra-Montesinos, G. J., and Wight, J. K. (2005). "Experimental Study on Seismic Behavior of High-Performance Fiber-Reinforced Cement Composite Coupling Beams," ACI Structural Journal, 102(1), 159-166.

Fortney, P. J., Rassati, G. A. and Shahrooz, B. M. (2008). "Investigation on Effect of Transverse Reinforcement on Performance of Diagonally Reinforced Coupling Beams," ACI Structural Journal, 105(6), 781-788.

Galano, L. and Vignoli, A. (2000). "Seismic Behavior of Short Coupling Beams with Different Reinforcement Layouts," ACI Structural Journal, 97(6), 876-885.

Harries, K. A., Fortney, P. J., Shahrooz, B.M. and Brienen, P. J. (2005). "Practical Design of Diagonally Reinforced Concrete Coupling Beams - Critical Review of ACI 318 Requirements," ACI Structural Journal, 102(6), 876-882.

Harries, K. A., Gong, B. and Shahrooz, B. M. (2000). "Behavior and Design of Reinforced Concrete, Steel, and Steel-Concrete Coupling Beams," Earthquake Spectra, 16(4), 775-799.

Kwan, A.K.H., and Zhao, Z.-Z. (2002). "Cyclic Behavior of Deep Reinforced Concrete Coupling Beams," Structures and Buildings, 152(3), 283-293.

Lequesne, R.D. (2011). Behavior and Design of High-Performance Fiber-Reinforced Concrete Coupling Beams and Coupled-Wall Systems, PhD. Dissertation, University of Michigan, Ann Arbor, MI, 277 p.

Lequesne, R. D., Setkit, M., Kopczynski, C., Ferzli, J., Cheng, M.-Y., Parra-Montesinos, G. J., and Wight, J. K. (2011). "Implementation of High-Performance Fiber Reinforced Concrete Coupling Beams in High-Rise Core-Wall Structures in the Seattle Area," American Concrete Institute SP-XXX, In Review, 13 pp.

Liao, W.-C., Chao, S.-H., Park, S.-Y. and Naaman, A. E. (2006). Self-Consolidating High-Performance Fiber-Reinforced Concrete (SCHPFRC)-Preliminary Investigation, Report No. UMCEE 06-02, 76 pp.

Naish, D., Fry, J. A., Klemencic, R. and Wallace, J. (2009). Reinforced Concrete Link Beams: Alternative Details for Improved Constructability, Report to Charles Pankow Foundation. UCLA-SGEL, 103 pp.

Parra-Montesinos, G. J. (2005). "High-Performance Fiber-Reinforced Cement Composites: An Alternative for Seismic Design of Structures," ACI Structural Journal, 102(5), 668-675.

Paulay, T. (1971). "Coupling Beams of Reinforced Concrete Shear Walls," Journal of the Structural Division, ASCE, 97(ST3), 843-861.

Paulay, T. and Binney, J. R. (1974). "Diagonally Reinforced Coupling Beams of Shear Walls," Shear in Reinforced Concrete, SP-42, American Concrete Institute, Detroit, MI, 2, 579-598.

Shiu, K. N., Barney, G. B., Fiorato, A. E., and Corley, W. G. (1978). "Reversing Load Tests of Reinforced Concrete Coupling Beams," Central American Conference on Earthquake Engineering Conferencia Centroamericana de Ingenieria Siemica, Proceedings, 239-249.

Tassios, T. P., Moretti, M., and Bezas, A. (1996). "On the Behavior and Ductility of Reinforced Concrete Coupling Beams of Shear Walls,” ACI Structural Journal, 93(6), 1-10.

Teshigawara, M., Kato, M., Sugaya, K. and Matsushima, Y. (1998). "Energy Absorption Mechanism and the Fluctuation of Shear Force in the Coupled Shear Walls," Structural Engineering World Wide 1998 - Proceedings, Paper Number T-186-5, Elsevier Science Ltd., 8 pp. 
Published version available at: http://ascelibrary.org/doi/abs/10.1061/(ASCE)ST.1943-541X.0000687

\section{FIGURES}

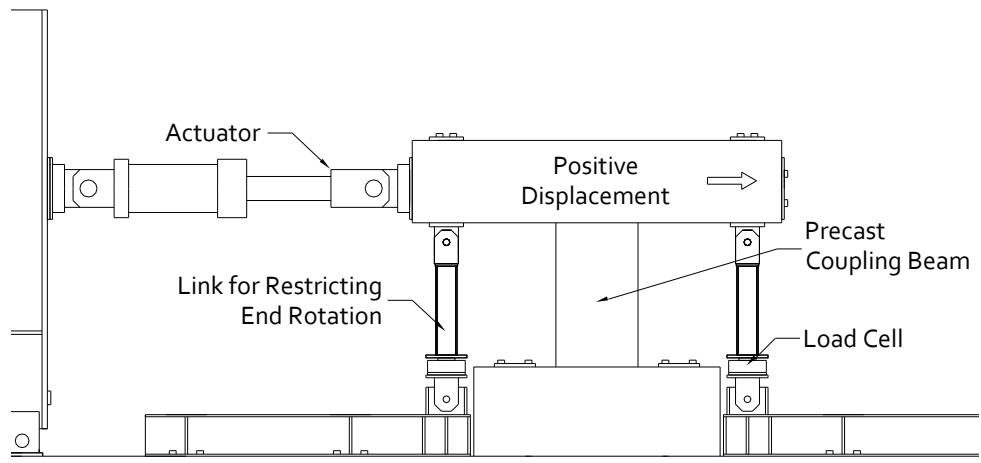

Figure 1. Coupling beam test setup

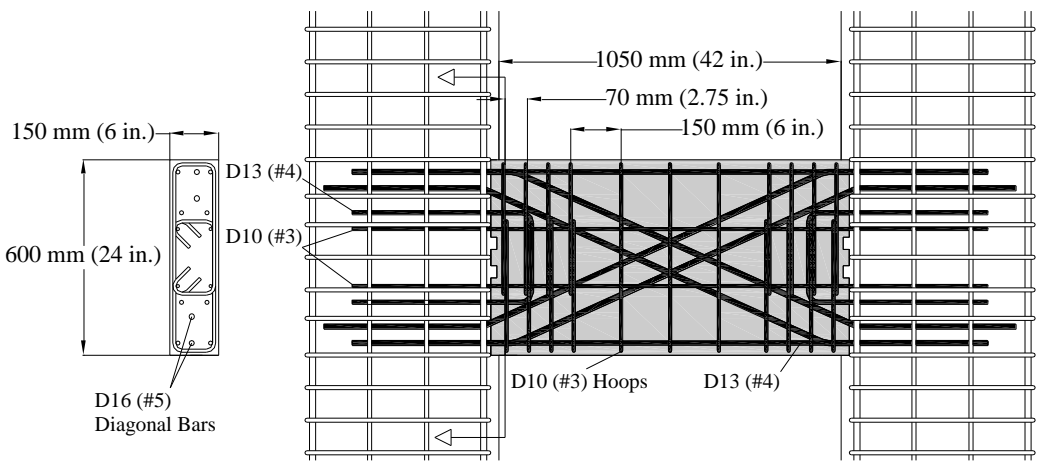

Figure 2. Coupling beam reinforcement for Specimen CB-2 (precast HPFRC shaded in gray)

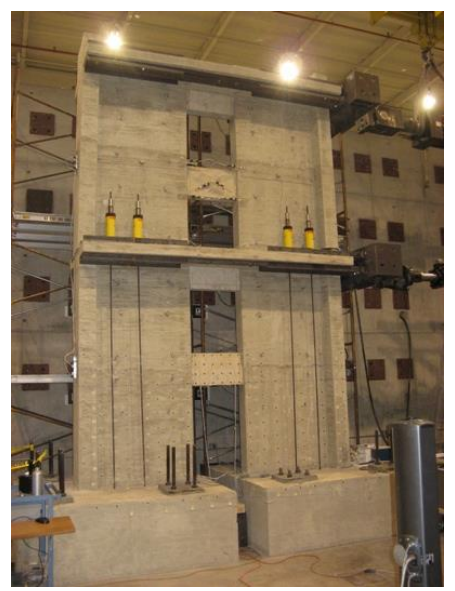

Figure 3. Coupled wall specimen 
- FINAL DRAFT -

Published version available at: http://ascelibrary.org/doi/abs/10.1061/(ASCE)ST.1943-541X.0000687

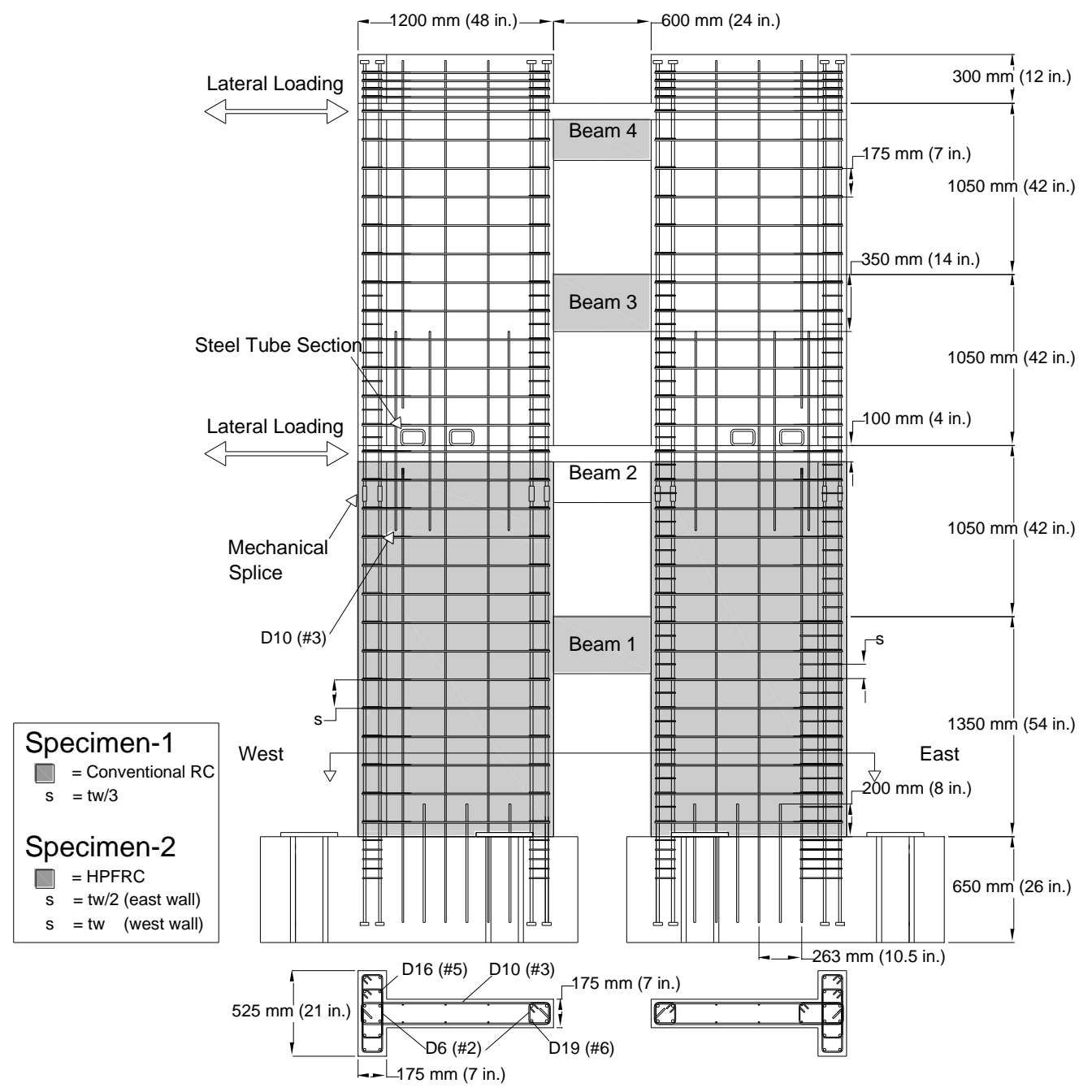

Figure 4. Coupled wall reinforcement

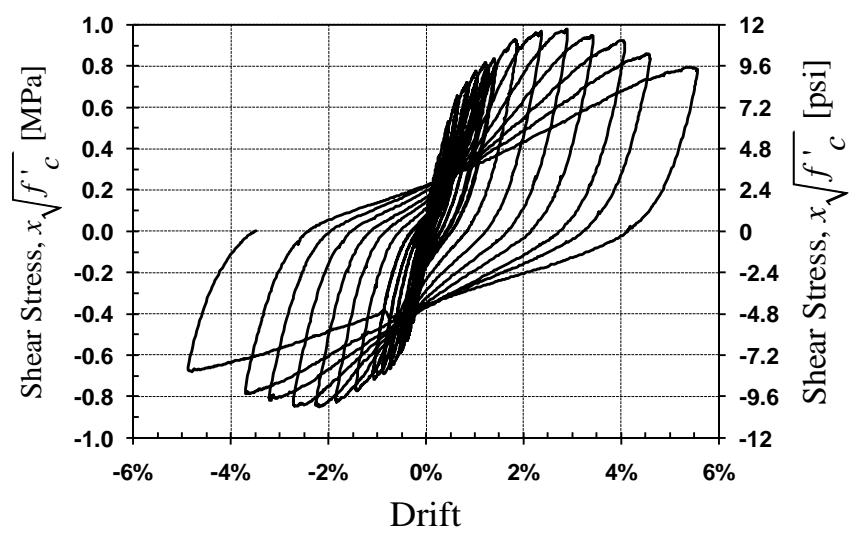

Figure 5. Specimen CB-2 shear stress versus drift response 
- FINAL DRAFT -

Published version available at: http://ascelibrary.org/doi/abs/10.1061/(ASCE)ST.1943-541X.0000687
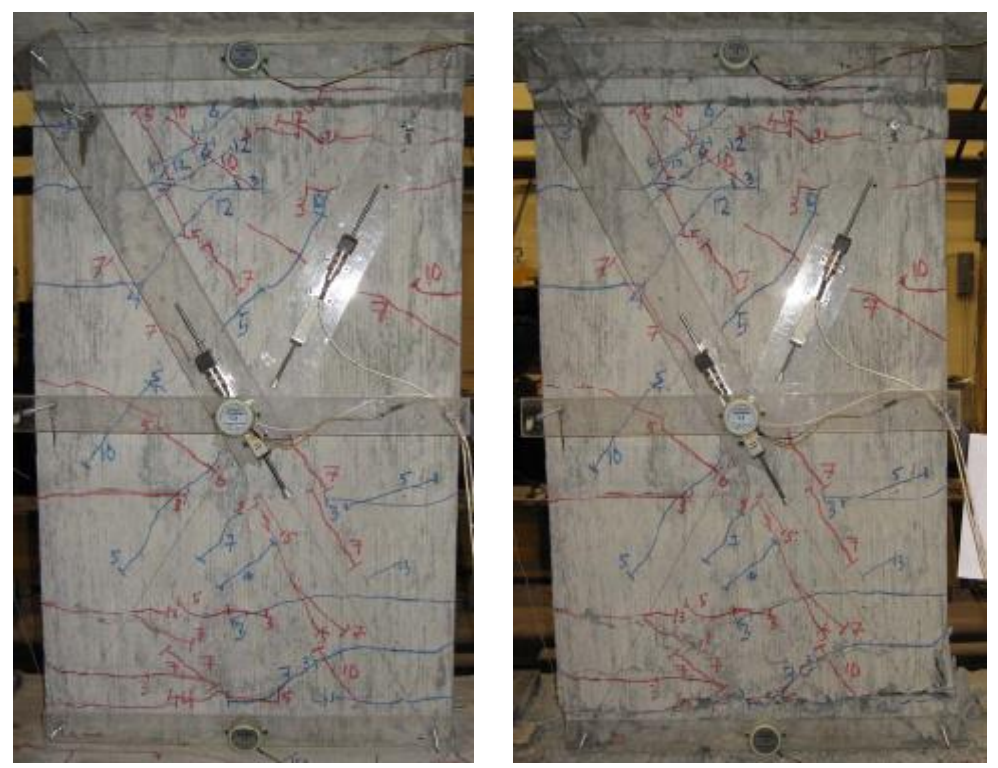

Figure 6. Damage of Specimen CB-2 at 3.5\% and 5.5\% drift, left and right, respectively

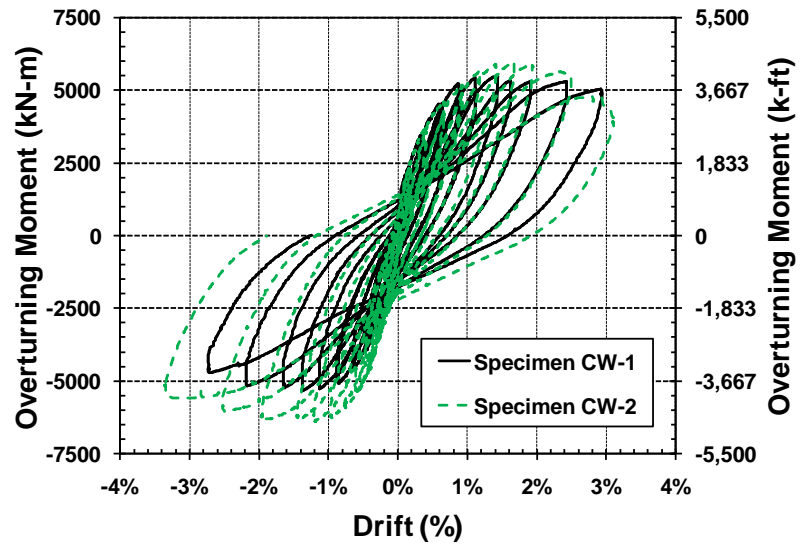

Figure 7. Overturning moment versus wall lateral drift response 
Published version available at: http://ascelibrary.org/doi/abs/10.1061/(ASCE)ST.1943-541X.0000687
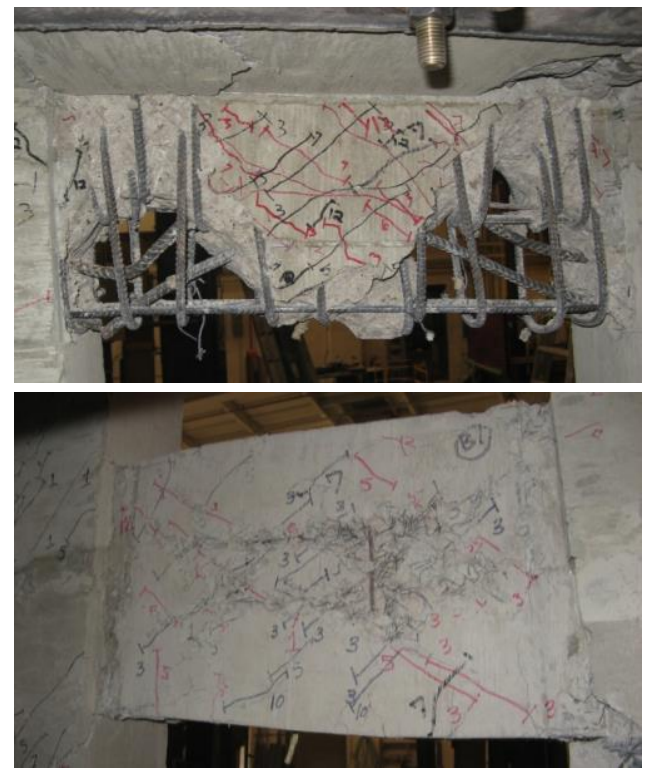

Figure 8. Reinforced concrete (top) and HPFRC (bottom) coupling beams at termination of testing

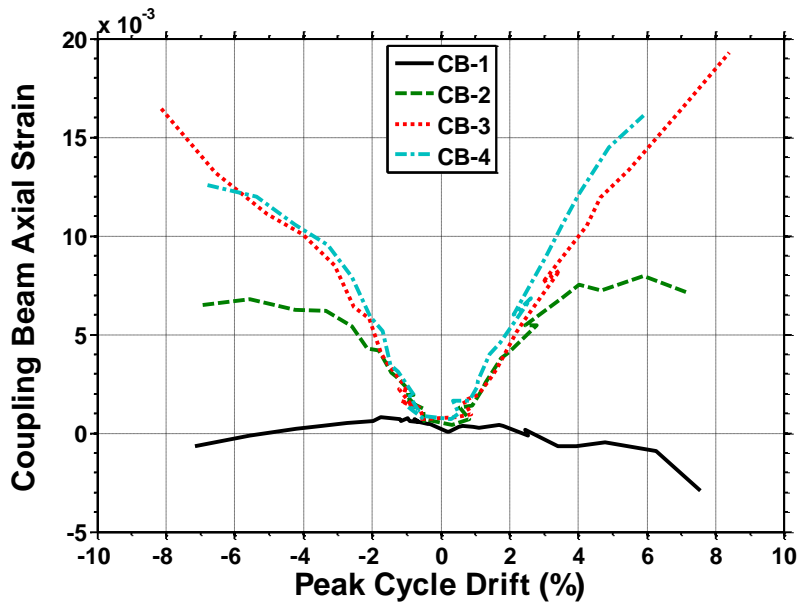

Figure 9. Axial strain in coupling beams plotted versus coupling beam drift for Specimens CW-1 
Published version available at: http://ascelibrary.org/doi/abs/10.1061/(ASCE)ST.1943-541X.0000687

\section{TABLES}

Table 1. HPFRC mixture proportions by weight

\begin{tabular}{|c|c|c|c|c|c|c|c|}
\hline Cement $^{1}$ & Fly Ash & Sand & Aggregate $^{2}$ & Water & Super-plasticizer & VMA $^{4}$ & Steel Fiber \\
\hline 1 & 0.875 & 2.2 & 1.2 & 0.8 & 0.005 & 0.038 & 0.32 \\
\hline
\end{tabular}

Table 2. High-strength hooked steel fiber properties (specified by manufacturer)

\begin{tabular}{|c|c|c|c|}
\hline Length, mm (in.) & Diameter, mm (in.) & L/d & $\begin{array}{c}\text { Minimum Tensile Strength, } \\
\text { MPa (ksi) }\end{array}$ \\
\hline $30(1.2)$ & $0.38(0.015)$ & 80 & $2300(333)$ \\
\hline
\end{tabular}

Table 3. Concrete properties 28 days after casting, and on the day of specimen testing (MPa; ksi)

\begin{tabular}{|c|c|c|c|c|c|c|c|c|c|}
\hline \multirow{3}{*}{ Location of Pour } & \multirow{3}{*}{$\begin{array}{c}\text { HPFRC } \\
(\mathrm{Y} / \mathrm{N})\end{array}$} & \multirow{3}{*}{$\begin{array}{c}\text { Design } \\
f_{c}^{\prime}\end{array}$} & \multicolumn{5}{|c|}{ 28-Day Tests } & \multirow{3}{*}{$\begin{array}{c}\text { Test Day } \\
f_{c}^{\prime}\end{array}$} & \multirow{3}{*}{\begin{tabular}{|c} 
Age \\
(days)
\end{tabular}} \\
\hline & & & \multirow{2}{*}{$f_{c}^{\prime}$} & \multicolumn{4}{|c|}{ ASTM 1609 Flexural Tests } & & \\
\hline & & & & $\sigma_{f c}$ & $\sigma_{\text {peak }}$ & $\sigma_{(\delta=L / 600)}$ & $\sigma_{(\delta=L / 150)}$ & & \\
\hline CB-1, Beam & $\mathrm{Y}$ & $41(6)$ & $38(5.5)$ & $4.4(0.64)$ & $6.4(0.93)$ & $6.6(0.95)$ & $4.1(0.60)$ & $45(6.5)$ & 78 \\
\hline CB-2, Beam & $\mathrm{Y}$ & $41(6)$ & $42(6.1)$ & $4.3(0.63)$ & $6.1(0.89)$ & $5.6(0.81)$ & $2.8(0.40)$ & $52(7.5)$ & 48 \\
\hline CB-3, Beam & $\mathrm{Y}$ & $41(6)$ & $34(5.0)$ & $4.8(0.69)$ & $5.9(0.86)$ & $5.2(0.75)$ & $2.3(0.33)$ & $34(5.0)$ & 41 \\
\hline CW-1, Wall $1^{\text {st }}$ lift & $\mathrm{N}$ & 28 & 3 & - & - & - & - & $.0)$ & 167 \\
\hline CW-1, Beam-1 & $\mathrm{Y}$ & $41(6)$ & $38(5.5)$ & $4.9(0.71)$ & $7.1(1.03)$ & $6.7(0.97)$ & $3.6(0.52)$ & $71(10.3)$ & 299 \\
\hline CW-1, Beam-2 & $\mathrm{N}$ & $41(6)$ & $37(5.3)$ & - & - & - & - & $68(9.8)$ & 308 \\
\hline CW-1, Beam-3 & $\mathrm{Y}$ & $41(6)$ & $38(5.5)$ & $4.9(0.71)$ & $7.1(1.03)$ & $6.7(0.97)$ & $3.6(0.52)$ & $71(10.3)$ & 299 \\
\hline CW-1, Beam-4 & $\mathrm{Y}$ & $41(6)$ & $41(6.0)$ & $5.7(0.83)$ & $7.7(1.12)$ & $7.2(1.05)$ & $4.1(0.60)$ & $74(10.8)$ & 302 \\
\hline CW-2, Wall $1^{\text {st }}$ lift & $\mathrm{Y}$ & $41(6)$ & $19(2.7)$ & - & - & - & - & $19(2.7)$ & 113 \\
\hline CW-2, Beam-1 & $\mathrm{Y}$ & $41(6)$ & $41(6.0)$ & $5.7(0.83)$ & $7.7(1.12)$ & $7.2(1.05)$ & $4.1(0.60)$ & $72(10.4)$ & 562 \\
\hline CW-2, Beam-2 & $\mathrm{N}$ & $41(6)$ & $46(6.6)$ & - & - & - & - & $63(9.2)$ & 566 \\
\hline CW-2, Beam-3 & $\mathrm{Y}$ & $41(6)$ & $38(5.5)$ & $4.9(0.71)$ & $7.1(1.03)$ & $6.7(0.97)$ & $3.6(0.52)$ & $72(10.4)$ & 559 \\
\hline CW-2, Beam-4 & $\mathrm{Y}$ & $41(6)$ & $41(6.0)$ & $5.7(0.83)$ & $7.7(1.12)$ & $7.2(1.05)$ & $4.1(0.60)$ & $72(10.4)$ & 562 \\
\hline
\end{tabular}

\section{CB: Coupling Beam; $\quad$ CW: Coupled Wall; $\quad$ (1 lift $=1$ story $)$}

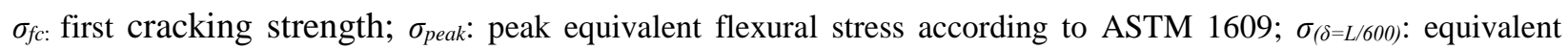
flexural stress at a mid-span deflection of $1 / 600$ of the beam span length $\mathrm{L} ; \sigma_{(\delta=L / 150)}$ : equivalent flexural stress at a mid-span deflection of $1 / 150$ of the beam span length $L$; 